\title{
The Effects of the Contact Activation System on Hemorrhage
}

\author{
Fabrício Simão and Edward P. Feener* \\ Research Division, Vascular Cell Biology, Joslin Diabetes Center, Harvard Medical School, Boston, MA, United States
}

The contact activation system (CAS) exerts effects on coagulation via multiple mechanisms, which modulate both the intrinsic and extrinsic coagulation cascades as well as fibrinolysis and platelet activation. While the effects of the CAS on blood coagulation measured as activated partial thromboplastin time shortening are well documented, genetic mutations that result in deficiencies in the expression of either plasma prekallikrein (PPK) or factor XII (FXII) are not associated with spontaneous bleeding or increased bleeding risk during surgery. Deficiencies in these proteins are often undiagnosed for decades and detected later in life during routine coagulation assays without an apparent clinical

\section{OPEN ACCESS}

Edited by:

Alvin H. Schmaier,

Case Western Reserve University, United States

Reviewed by: Coen Maas, University Medical Center Utrecht, Netherlands

Owen McCarty,

Oregon Health \& Science University, United States

Jonas Emsley,

University of Nottingham,

United Kingdom David Gailani,

Vanderbilt University, United States

*Correspondence:

Edward P. Feener edward.feener@joslin.harvard.edu

\footnotetext{
Specialty section:

This article was submitted to Hematology,

a section of the journal

Frontiers in Medicine
}

Received: 25 March 2017 Accepted: 12 July 2017

Published: 31 July 2017

Citation:

Simão F and Feener EP (2017) The Effects of the Contact Activation System on Hemorrhage. Front. Med. 4:121. doi: 10.3389/fmed.2017.00121 phenotype. Increased interest in the CAS as a potentially safe target for antithrombotic therapies has emerged, in large part, from studies on animal models with provoked thrombosis, which have shown that deficiencies in PPK or FXII can reduce thrombus formation without increasing bleeding. Gene targeting and pharmacological studies in healthy animals have confirmed that PPK and FXII blockade does not cause coagulopathies. These findings support the conclusion that CAS is not required for hemostasis. However, while deficiencies in FXII and PPK do not significantly affect bleeding associated with peripheral wounds, recent reports have demonstrated that these proteins can promote hemorrhage in the retina and brain. Intravitreal injection of plasma kallikrein (PKal) induces retinal hemorrhage and intracerebral injection of PKal increases intracranial bleeding. PPK deficiency and PKal inhibition ameliorates hematoma formation following cerebrovascular injury in diabetic animals. Moreover, both PPK and FXII deficiency are protective against intracerebral hemorrhage caused by tissue plasminogen activator-mediated thrombolytic therapy in mice with thrombotic middle cerebral artery occlusion. Thus, while the CAS is not required for hemostasis, its inhibition may provide an opportunity to reduce hemorrhage in the retina and brain. Characterization of the mechanisms and potential clinical implications associated with the effects of the CAS on hemorrhage requires further consideration of the effects of PPK and FXII on hemorrhage beyond their putative effects on coagulation cascades. Here, we review the experimental and clinical evidence on the effects of the CAS on bleeding and hemostatic mechanisms.

Keywords: kallikrein-kinin system, hemorrhage, hemostasis, factor XII, plasma kallikrein, contact activation system, coagulation

\section{INTRODUCTION}

The contact activation system (CAS) represents a group of plasma proteins, including factor XII (FXII), plasma prekallikrein (PPK), and high molecular weight kininogen (HK) that promotes inflammation and coagulation upon contact of blood with an activating surface or protease $(1,2)$. CAS activation is initiated by interactions of FXII with a negatively charged surface or a protease 
that induces a conformational change in FXII leading to its proteolytic cleavage and the generation of the serine protease FXIIa $(3,4)$. The two primary substrates for FXIIa are PPK and factor XI (FXI). FXIIa-mediated cleavage of PPK results in its zymogen activation to the serine protease plasma kallikrein (PKal), which converts FXII to FXIIa and thereby provides positive feedback amplification of the CAS. The effects of the CAS on inflammation, vascular permeability, and edema are primarily attributed to the Kallikrein-Kinin System. This system involves PKal-mediated cleavage of $\mathrm{HK}$ to generate the nonapeptide hormone bradykinin $(\mathrm{BK})$, which activates $\mathrm{B} 2$ receptors (B2R) that are expressed on a variety of vascular, neuronal, and immune cell types. Binding of BK to B2R activates proinflammatory signaling pathways that dilate vessels, induce chemotaxis of neutrophils, and increase vascular permeability $(5,6)$. C1-inhibitor $(\mathrm{C} 1$-INH) is the primary physiological inhibitor of both FXIIa and PKal, and C1-INH deficiency facilities CAS activation and BK-mediated angioedema (7). Both PKal and the B2R are clinically significant mediators of hereditary angioedema (HAE) $(8,9)$. In addition to its effects on inflammation and vascular permeability, BK has been shown to induce expression of both tissue factor (TF) and tissue plasminogen activator (tPA), which activates the extrinsic coagulation pathway and fibrinolysis, respectively (10-13) (Figure 1).

The acute effects of the CAS on coagulation have been primarily attributed to FXIIa-mediated activation of FXI and thereby the intrinsic coagulation pathway leading to fibrin

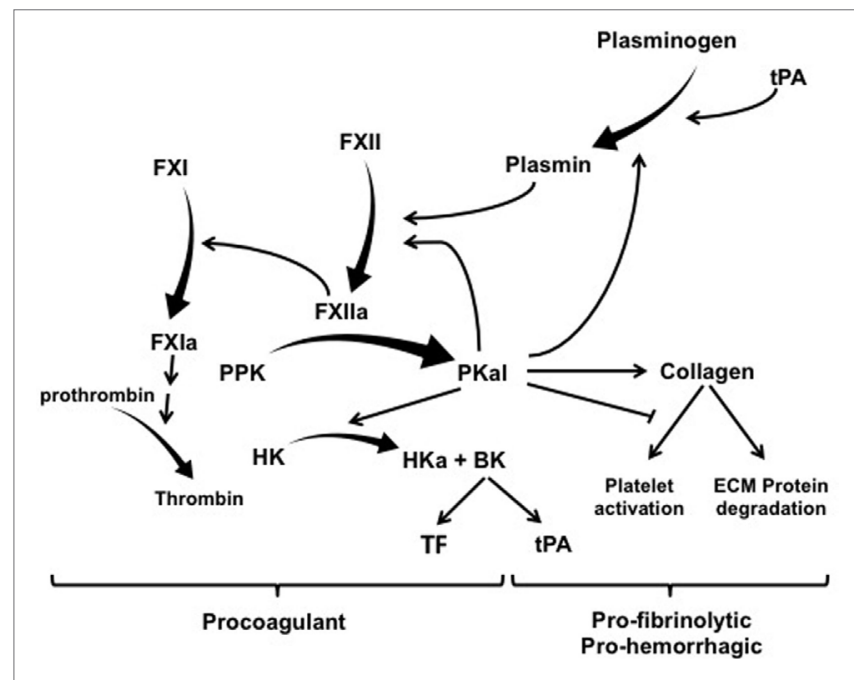

FIGURE 1 | The contact activation system has multiple effects on coagulation, hemorrhage, and fibrinolysis. Exogenous tPA activates plasminogen and thereby mediated both plasmin-mediated fibrinolysis and activation of factor XII (FXII). FXIla mediates its procoagulant effects by cleaving factor XI (FXI) into FXla, which leads to the generation of thrombin. FXlla also cleaves PPK into PKal, which exerts a combination of effect on thrombosis, fibrinolysis, and hemorrhage. PKal's effects on hemorrhage have been attributed to its direct and indirect effects on collagen cleavage. In addition, PKal can also interferes with collagen-induced platelet activation, which can impair hemostasis. Activation of the kallikrein-kinin system generates bradykinin, which stimulates expression of both TF and TPA. Abbreviations: HK, high molecular weight kininogen; PPK, plasma prekallikrein; PKal, plasma kallikrein; BK, bradykinin; ECM, extracellular matrix; tPA, tissue plasminogen activator; TF, tissue factor. generation. Although the biochemical roles of PKal and FXIIa as upstream triggers for the intrinsic coagulation system were recognized over 50 years ago (14), the clinical significance of these factors on thrombosis and hemorrhage is not fully understood. It is well documented that CAS blockade results in prolonged coagulation times in the activated partial thromboplastin time (aPTT) assay (15). The absence of thrombotic and hemostatic abnormalities in individuals with genetic PPK or FXII deficiency has suggested that the CAS plays a minimal role in physiological coagulation. However, information from rare case studies of individuals with deficiencies in individual components of the CAS has provided limited insight into the potential clinical significance of PKal and FXIIa in coagulation in specific diseases. This is further complicated by the interpretation of acquired and mild CAS component deficiencies, which may reflect the activation of the system rather than its suppression. Key observation from studies of humans with genetic FXII and PPK deficiencies is the absence of spontaneous bleeding disorders and increased bleeding risk during surgery, which are observed in individuals with genetic mutations in downstream in the intrinsic pathway, such as FIX (hemophilia B) and FXI (hemophilia C). The main evidence suggesting that CAS inhibition can reduce pathological thrombosis without increasing bleeding has emerged from studies using PPK and FXII-deficient animals with acute and artificially provoked coagulation (16-20). These clinical and experimental findings have generated increased interest in the potential therapeutic opportunities of targeting the CAS in thrombosis. Indeed the observations of the blockade of the CAS results in reduced thrombosis without a concomitant increase in bleeding in preclinical studies have suggested that therapies that inhibit the CAS may offer novel strategies for safe and effective antithrombotics. Moreover, recent studies suggest that blockade of the CAS can improve hemostasis in the retina and brain. In this review, we discuss emerging understanding of the role of CAS on bleeding and hemostasis and the clinical implications of this research.

\section{HEMOSTASIS}

Hemostasis is the process that prevents blood loss following vascular injury. The mechanisms of hemostasis involve both serial and parallel events, mediated by the interactions between circulating factors in blood with components of activated or injured vascular tissue. Given the critical nature of hemostasis, the system has evolved both redundant and reinforcing mechanisms that facilitate both rapid and stable cessation of blood loss. The sequence of events and the relative contributions and requirements of individual coagulation components may vary according to the affected tissue and type of injury, and possibly also the animal species. While thrombosis and hemostasis share a host of coagulation factors, the etiology of these processes has important distinctions, which may create therapeutic opportunities to selectively target thrombosis without affecting hemostasis.

Although animal models do not fully recapitulate the complexity of human physiology and disease, studies on animals with targeted deficiencies in coagulation factors have provided insight into contributions of individual components of coagulation in 
hemostatic mechanisms. Multiple approaches are used to quantify hemostatic responses in rodents, including tail tip bleeding, cuticle bleeding, and tail vein transection assays. Deficiencies in FXII and PPK in healthy animals exert little or no effect on tail bleeding time despite aPTT prolongation (Table 1), in contrast to prothrombin deficiency, which markedly increases blood loss in tail wound models (21).

Deficiencies in downstream factors in the intrinsic cascade (such as FIX and FXI) result in bleeding disorders, demonstrating their role in physiological hemostasis. Paradoxically, deficiencies in the CAS factors FXII, PPK, or HK, which trigger coagulation in vitro and contribute to thrombosis in animal models, are not associated with a bleeding diathesis. However, while surgical interventions provide a general assessment of hemostasis, it does not fully model the potential contributions of the CAS in all hemorrhagic conditions. Indeed, recent studies have suggested that the CAS may play an important role in hemorrhage in the retina and brain in certain diseases $(17,20,30)$.

\section{Effects of Kallikrein-Kinin System on Platelet Activation}

The initial steps in hemostasis involve vasocontraction and the local aggregation of platelets to rapidly restrict bleeding at the site of endothelium disruption. Vascular spasm and vasoconstriction, which reduces local blood flow, is triggered by factors released from vascular smooth muscle, endothelial cells, and platelets, and reflexes initiated by the local sympathetic nervous system. Platelets adhere via glycoprotein VI (GPVI) receptors to exposed basement membrane collagen at the site disrupted endothelium to initiate platelet aggregation. This process leads to tethering and activation of platelets, additional platelet receptor-collagen interactions, and platelet plug formation. GPVI play a critical role in normal hemostasis, and its deficiency results in abnormal platelet-responses to collagen and mild bleeding tendency (31).

A report by Liu et al. (17) has shown that PKal inhibits collagen-induced platelet aggregation. PKal also interferes with platelet aggregation induced by collagen-related peptide, a GPVI agonist, but not by convulin; a snake venom toxin that is a collagen-independent GPVI agonist. Moreover, PKal does not alter either thrombin's or ADP's effects on platelet aggregation.
These findings suggest that PKal's effects on platelet activation were specific to GPVI interactions with collagen. Interestingly, the inhibitory effects of $\mathrm{PKal}$ on collagen-induced platelet activation were not mimicked with PPK, suggesting that the activate form of this protein is required for its inhibitory effect. These findings suggest that PKal binding to collagen in the basement membrane at the site of endothelium disruption interferes with GPVI-mediated platelet activation during initial stages of hemostasis. PKal binding to collagen and its effects on platelet aggregation are increased at elevated glucose concentrations, suggesting that hyperglycemia enhances PKal inhibition of collagen-induced platelet aggregation and thereby may contribute to hematoma expansion in diabetes. Although the mechanism by which glucose increases the binding of collagen to PKal has not been identified, previous reports have suggested that an exposure of collagen to hyperglycemia can alter collagen conformation and facilitate protein binding (32). Interestingly, hyperosmolar concentrations of mannitol, a treatment commonly used to reduce brain edema following stroke, increased hematoma expansion in non-diabetic rats and enhanced PKal's inhibitory effects on collagen-induced platelet aggregation in vitro. These results suggest that plasma osmolality may alter PKal's effects on coagulation. The mechanism of PKal interference of collagen-platelet GPVI binding appears analogous to the effects of anopheline antiplatelet protein in the saliva of the malaria vector mosquito, which also interferes with collagen-induced platelet activation and hemostasis (33). Further studies are needed to map the domain on PKal that binds to collagen and the factors that modulate this binding. In addition to altering platelet interactions, PKal binding to collagen may retain this enzyme at the site of vascular injury to facilitate its local inflammatory effects. In contrast to the inhibitory effects of PKal on hemostasis, FXII activation by collagen and laminin in the subendothelial matrix can lead to thrombin generation, which may promote secondary mechanisms of platelet activation at the site endothelium disruption $(34,35)$. Although these findings suggest that the CAS can exert both positive and negative effects on platelet activation during hemostasis, gene targeting and pharmacological studies indicated that blockade of CAS reduces cerebral hemorrhage, which is a primary area of concern regarding bleeding in patients on antithrombotic therapy.

TABLE 1 | Effects of contact activation system inhibition and deficiencies in experimental models.

\begin{tabular}{|c|c|c|c|c|c|}
\hline Condition & aPTT & Tail bleeding & Spontaneous bleeding & Species & Reference \\
\hline $\mathrm{FXII}^{-/-}$ & Prolonged & No changes & Not reported & Mice & Renne et al. (16) \\
\hline $\mathrm{FXII}{ }^{-/-}$ & Prolonged & No changes & Not reported & Mice & Iwaki et al. (22) \\
\hline Anti-FXII (9A2 and 15H8) & Prolonged & No changes & No & Primate & Matafonov et al. (23) \\
\hline FXII ASO & Not reported & No changes & No & Mice & Revenko et al. (24) \\
\hline FXIII-/- or Infestin-4 & Prolonged & No changes & No & Mice & Nickel et al. (25) \\
\hline Infestin-4 & Prolonged & No changes & No & Mice & Hagedorn et al. (26) \\
\hline $\mathrm{FXII}^{-/-}$or FXII sRNAi & Prolonged & No changes & No & Rat & Cai et al. (27) \\
\hline PPK ASO & Not reported & No changes & No & Mice & Revenko et al. (24) \\
\hline $\mathrm{Klkb}^{-/-}$ & Prolonged & No changes & Not reported & Mice & Liu et al. (17) \\
\hline PPK ASO & Prolonged & No changes & No & Mice & Bird et al. (18) \\
\hline Kng1 ${ }^{-/-}$ & Prolonged & No changes & Not reported & Mice & Merkulov et al. (28) \\
\hline $\mathrm{Bdkrb2}^{-/-}$ & Prolonged & Prolonged & Not reported & Mice & Shariat-Madar et al. (29) \\
\hline
\end{tabular}

ASO, antisense oligonucleotide; aPTT, activated partial thromboplastin time; infestin-4 is an FXIla inhibitor; 9 A2 and 15 H8 are anti-FXII inhibitory antibodies; FXII, factor XII; PPK, plasma prekallikrein. 


\section{Effects of Kallikrein-Kinin System on Fibrin Formation}

Stabilization of the nascent thrombus involves additional coagulation factors that generate and crosslink fibrin, which stabilizes nascent platelet plugs. FXIIa-mediated activation of FXI results in the activation of the intrinsic coagulation cascade, leading to thrombin activation and fibrinogen cleavage and the stabilization and expansion of clots. Although FXIIa can serve as a trigger to activate the intrinsic pathway from the CAS, positive feedback activation of FXI by thrombin can also activate this pathway following extrinsic activation (36-39). Thus, while FXII appears to contribute to arterial thrombus formation and growth, at least in animal models, FXII does not appear to be required for clot formation during hemostasis. Activated platelets actively contribute to this secondary hemostatic process by generating surface-bound polyphosphate nanoparticles (40), which activates FXII and thereby promotes local fibrin generation by the clot. Although FXII, PPK, or HK deficiency is not associated with bleeding, FXI deficiency in patients is associated with mild bleeding, suggesting that the role of FXI in hemostasis is independent of the CAS. The upstream activation of FXI by thrombin may explain why FXII is not required for hemostasis in contrast to FXI, where its deficiency is associated with hemophilia C.

Clinical trials and epidemiologic data indicate that FXI contributes to thromboembolic diseases. Studies with animal models also suggest that the activation of FXI by FXIIa promotes pathological thrombus formation (41). Furthermore, "exposed" collagen also initiates the contact phase of coagulation by binding to FXII and enhances coagulation in vitro (35). The conversion into active FXIIa is dependent on repetitive negative charge exposed by collagen fibrils (42). van der Meijden and colleagues (43) showed that collagen potentiates thrombus formation via binding to FXII, leading to its activation and subsequent FXI activation. This report suggests a dual role for collagen in thrombin generation by stimulating platelet activation via GPVI and by direct effects on FXII. In addition, FXIa-mediated thrombin activation may contribute to clot stability thrombin-activatable fibrinolysis inhibitor-mediated removal of lysine residues on fibrin, which increases its resistance to fibrinolysis (44). Moreover, FXIa proteolytically degrades and neutralizes TF pathway inhibitor, which can promote thrombin generation via the extrinsic pathway (45). Recently, Stavrous and colleagues (13) demonstrated that PPK deficiency in mice increase prostacyclin through Sirt1 and KLF4, which reduced vascular TF expression and thrombosis. Thus, while CAS's effects on both the intrinsic and extrinsic pathways contribute to clot stabilization, mechanistic redundancy contributing to fibrin generation minimizes the requirements of the CAS in this process.

\section{EFFECTS OF PPK, FXII, AND C1-INH DEFICIENCY ON COAGULATION IN HUMANS}

Most reports have indicated that individuals with severe deficiencies in either PPK or FXII do not display abnormalities in either thrombosis or bleeding (Table 2), and often go undiagnosed for decades without apparent clinical phenotype. The absence of a bleeding diathesis in FXII and PPK deficiencies appears to contradict the key role of these proteins in coagulation via the intrinsic pathway in vitro, and this has left the physiological significance of the CAS in coagulation and thrombosis unclear. However, CAS could be a trigger for thrombosis associated with extracorporeal circuits (46) and cardiopulmonary bypass (47) by exposing blood to artificial surfaces, non-physiological shear stress, and osmotic forces. Administration of an antibody that neutralizes FXIIa (3F7) has been shown to have a similar effect as heparin in preventing thrombosis during extracorporeal circuits (48).

Activation of FXII by kaolin (negatively charged aluminum silicate particulate) provides the basis for the aPTT, a clinical clotting assay, which is widely used to assess the integrity of the intrinsic pathway and to monitor anticoagulation with heparin. Deficiencies in FXII, PPK, and HK results in markedly prolonged aPTT and no increases in spontaneous bleeding or impairment in hemostasis (Table 2). Normalization of a severely increased aPTT (>120 s) after prolonged preincubation with aPTT reagent occurred in plasma deficient in PPK but not in plasma deficient in FXII, HK, FXI, FIX, FVIII, and Passovoy trait plasma (a deficiency characterized by abnormal coagulation affecting the intrinsic coagulation system) or plasma containing lupus anticoagulant. Autoactivation of FXII in PPK-deficient plasma in the presence of kaolin paralleled the normalization of aPTT. The addition of OT-2, a monoclonal antibody neutralizing FXII, prevents the normalization of aPTT (66). These results suggest that autoactivation of FXII is responsible for normalization of a severely prolonged aPTT upon increased preincubation time in PPK-deficient plasma.

In humans, PPK deficiency is not associated with hemostatic disorders, indicating $\mathrm{PKal}$ is not required for hemostasis. Although some case reports have associated FXII deficiency with prothrombotic events, a clinical study failed to demonstrate a significant correlation between increased risk of thrombosis and FXII deficiency (78). Girolami and colleagues (79) re-evaluated case reports on FXII deficiency and thrombosis. They showed that, in most cases, FXII deficiency was associated with other congenital or acquired prothrombotic risk factors. While these studies indicate that the CAS is not essential for either thrombosis or hemostasis, individuals with genetic deficiencies in the CAS are rare and it is not possible to ascertain from the anecdotal clinical information whether PKal and FXIIa could have significant roles in thrombosis or hemostasis associated with specific clinical indications.

C1-inhibitor is the primary endogenous inhibitor of both PKal and FXIIa. HAE is a rare genetic disease caused by deficiencies in C1-INH concentration (Type I) or C1-INH activity (Type II) (80). HAE has a prevalence of approximately 1:50,000 and is characterized by episodes of vasogenic edema, which vary in severity and affected tissue, and can become life threatening when affecting the larynx. The primary mechanism for this disease is the uncontrolled activity of PKal, which results in increased cleavage of $\mathrm{HK}$, and increased production of BK. While the molecular and physiological triggers for the onset of attacks are not fully understood, increased levels of FXIIa is observed 
TABLE 2 | Case reports of deficiencies in contact activation system proteins.

\begin{tabular}{|c|c|c|c|c|}
\hline Deficiency & aPTT & Thrombosis and clinical presentation & Spontaneous bleeding & Reference \\
\hline FXII & Prolonged & Bilateral femoral vein thrombosis & No & Cei et al. (49) \\
\hline FXII (mild) & Slightly prolonged & Venous thrombosis & No & Lessiani et al. (50) \\
\hline FXII & Prolonged & Coronary artery bypass grafting & No & Conaglen et al. (51) \\
\hline FXII & Prolonged & Arterial and venous thrombosis & No & Hellstern et al. (52) \\
\hline FXII & Prolonged & Coronary artery bypass grafting & No & Moorman et al. (53) \\
\hline FXII (mild) & Prolonged & $\begin{array}{l}\text { Occlusive thrombus in the circumflex and anterior descending } \\
\text { arteries }\end{array}$ & No & Penny et al. (54) \\
\hline FXII & Prolonged & Coronary artery bypass grafting & No & Rygal and Kuc (55) \\
\hline FXII & Prolonged & Coronary artery disease & No & Cronbaugh et al. (56) \\
\hline FXII & Prolonged & Coronary artery bypass grafting & No & Salmenper et al. (57) \\
\hline FXII & Prolonged & No thrombosis & No & van Veen et al. (58) \\
\hline FXII & Prolonged & Coronary artery disease & No & Wood (59) \\
\hline FXII (mild) & Prolonged & Bilateral lower limb deep vein thrombosis & No & Vergnes et al. (60) \\
\hline FXII & Prolonged & Retinal venous thrombosis & No & Borrego-Sanz et al. (61) \\
\hline FXII (mild) & Prolonged & Deep vein thrombosis, after abdominal surgery & No & Cornudella et al. (62) \\
\hline FXII & Prolonged & Cardiopulmonary bypass & No & Gerhardt et al. (63) \\
\hline PPK & Prolonged & No thrombosis & No & van Veen et al. (58) \\
\hline PPK & Prolonged & Coronary artery disease & No & Oram et al. (64) \\
\hline PPK & Prolonged & No thrombosis & No & Cankovic et al. (65) \\
\hline PPK & Prolonged & No thrombosis & No & Asmis et al. (66) \\
\hline PPK & Prolonged & No thrombosis & No & Maak et al. (67) \\
\hline PPK & Prolonged & No thrombosis & No & DeLa Cadena (68) \\
\hline PPK & Prolonged & Ischemic stroke & No & Francois et al. (69) \\
\hline PPK & Prolonged & No thrombosis & Idiopathic thrombocytopenic purpura & Nakao et al. (70) \\
\hline PPK & Prolonged & No thrombosis & No & Lombardi et al. (71) \\
\hline PPK & Prolonged & No thrombosis & No & Wynne Jones et al. (72) \\
\hline PPK & Prolonged & No thrombosis & No & Poon et al. (73) \\
\hline $\mathrm{HK}$ & Prolonged & No thrombosis & No & Cankovic et al. (65) \\
\hline $\mathrm{HK}$ & Prolonged & Cardiopulmonary bypass & No & Davidson et al. (74) \\
\hline $\mathrm{HK}$ & Prolonged & No thrombosis & No & Lefrere et al. (75) \\
\hline $\mathrm{HK}$ & Prolonged & No thrombosis & No & Stormorken et al. (76) \\
\hline $\mathrm{HK}$ & Prolonged & Vertebral-basilar artery thrombosis following trauma & No & Krijanovski et al. (77) \\
\hline
\end{tabular}

aPTT, activated partial thromboplastin time; FXII, factor XII; PPK, plasma prekallikrein; HK, high molecular weight kininogen; NA, not available.

Mild, 50 to $20 \%$ of control.

in this disease (81) which suggest that attacks are mediated by the CAS. Since HAE is not associated with coagulopathies, this disorder provides an opportunity to evaluate the effects of the CAS on downstream coagulation pathways, independent of confounding input associated with comorbidities of thrombosis and hemostasis. Indeed, plasma obtained from HAE subjects during edematous attacks display shortened aPTT, compared to plasma collected from these subjects during remission (82, 83). In addition, FXIa activity, prothrombin fragment $\mathrm{F} 1+2$, thrombin-anti-thrombin complex, and FVIIa are elevated in subjects with HAE during an attack $(81,83,84)$. The absence of apparent clinical coagulopathies in HAE during attacks could be due to compensatory mechanisms that occur during attacks and/ or requirements of additional factors not activated by the CAS to initiate or promote thrombosis formation.

\section{EFFECTS OF PPK AND FXII DEFICIENCY ON COAGULATION IN RODENTS}

Consistent with PPK and FXII deficiencies in humans, PPK, and FXII-deficient mice display prolonged aPTT (Table 1). Pharmacological inhibition of FXIIa and deficiency in either FXII or HK genes have been shown to protect mice from experimentally induced thrombosis $(16,24,26,28)$, indicating the potential role of the CAS in thrombotic disease. Cheng and colleagues (41) demonstrated that a neutralizing antibody to FXI (14E11) had a comparable effect to FXI deficiency in a $\mathrm{FeCl}_{3}$ model of thrombosis. Antibody 14E11 binds FXI and interferes with FXI activation by FXIIa, suggesting that thrombus formation in this model requires FXI activation by FXIIa. These data have generated interest in developing strategies to therapeutically inhibit FXIIa and contact activation to treat or prevent thromboembolic disorders. Interestingly, thrombosis protection in mice was greater with FXII deficiency than with FXI deficiency, suggesting that FXII may exert effects on coagulation that do not require FXI (41).

Factor XII-deficient mice showed defective thrombus formation (16) and protective effect against experimental ischemic stroke (85) and pulmonary embolism (86). Intravital microscopy showed that the initial adhesion of platelets at the site of injury is not affected by FXII deficiency, although the formation and stabilization of three-dimensional thrombi is impaired (16). Similar defective thrombus formation was observed in $\mathrm{FXI}^{-1-}$ mice $(87,88)$. Furthermore, FXII deficiency or pharmacological inhibitor of FXIIa showed decreased infarct volume without the presence of intracerebral hemorrhage (ICH) (85). Reconstitution of FXIIdeficient mice with human FXII protein restored susceptibility for ischemic stroke. A recent report by Nickel and colleagues 
(25) has shown that prostasomes released from prostate cancer activated FXII and that both FXI- and FXII-deficient mice are protected against cancer-associated thrombosis (25). However, the observation that PPK-deficient mice were not protected in the prostasome-induced thrombosis model is surprising and appears different than other CAS-associated thrombosis models, which require PPK. Taken together, these findings suggest that coagulation mediated by intrinsic pathway through FXII is critical for pathological thrombus formation in certain conditions without being relevant for hemostasis.

In addition, the CAS mediates effects on thrombosis via the kallikrein-kinin system. Genetic ablation of Kng1 in mice showed a delayed time to carotid artery occlusion in a laser injury model (28). BKB2 $\mathrm{R}^{-1-}$ mice have prolonged bleeding time and delayed carotid artery occlusion times in the rose Bengal thrombosis model and these effects were attributed to increased expression of angiotensin receptor 2 and elevated nitric oxide and prostacyclin levels (29). These findings suggest that the BK system contributes to the effects of the CAS on coagulation.

\section{POTENTIAL ROLE OF THE KALLIKREIN- KININ SYSTEM IN HEMORRHAGE}

Components of the CAS are normally restricted from contact with the vascular basement membrane by the endothelium. Vascular hyperpermeability enables components of the CAS to leak into the subendothelial space and gain contact with the basement membrane. The potential functions of the CAS in the subendothelial space have received relatively little attention. PKal binds to collagen (89), which may contribute to the retention of its catalytic activity in the extracellular matrix (ECM) at the site of injury and thereby enable local amplification of its inflammatory and edematous actions. Moreover, PKal in this subendothelial space may have additional substrates and functions, which are not apparent in the plasma.

\section{Diabetic Retinopathy}

In diabetic retinopathy, retinal vascular hyperpermeability can lead to diabetic macular edema (DME); the leading cause of vision loss in working-age adults in most developed countries (90). Proteomic analysis of vitreous fluid from patients with DME has revealed increased concentrations of PPK, HK, and FXII in this fluid compared with people without DME (91-93). These increases have been attributed to the increased diffusion of these CAS components from the blood into the neuroretinal interstitial fluid and vitreous humor. Recent reports have shown that intravitreal injection of $\mathrm{PKal}$ alters both retinal vascular function and ultrastructure. A single injection of PKal in the vitreous of rats induced retinal vascular hyperpermeability and retinal layer thickening (94), whereas two injections of purified PKal into the vitreous caused retinal bleeding that appeared similar to retinal microhemorrhages that occur in diabetic retinopathy (30). While injections of BK mimicked PKal's effect on retinal permeability and thickening at $24 \mathrm{~h}$ repeated injections of BK did not cause retinal bleeding at $48 \mathrm{~h}$. These findings suggest that $\mathrm{PKal}$ in the subendothelial space may contribute to retinal hemorrhages, which are a hallmark of advanced stages of diabetic retinopathy. Proteomics has been used to investigate the effects of PKal that may contribute to this disruption of the blood-retinal barrier. Analyses of conditioned media from both cultured pericytes and astrocytes incubated with PKal have revealed increases in proteolytic fragments of ECM proteins, including multiple collagen isoforms $1-6$, laminin $\beta 1$ and $\gamma 1$, nidogen 1 and 2 , and fibronectin, compared with conditioned media from cells that were not exposed to $\mathrm{PKal}(30,95)$. In a purified system, PKal was shown to cleave COL4A, suggesting that PKal can proteolytically cleave collagen (30). Although the causes of retinal bleeding in diabetic retinopathy are not yet known, these studies suggest a mechanism by which vascular permeability, via the extravasation of PKal, may contribute to retinal hemorrhage, in part, mediated by the proteolytic degradation of the vascular basement membrane.

\section{Cerebral Hematoma Formation}

Diabetes and hyperglycemia are associated with increased ICH and worse clinical outcomes following a cerebrovascular accident (96-98). Diabetes and acute hyperglycemia in non-diabetic rodents increase hematoma formation in an experimental model of ICH (17). In this report by Liu et al., intracerebral injection of autologous blood induced hematoma expansion, which was ameliorated by PPK deficiency and PKal inhibition. Moreover, intracerebral injection of purified PKal mimicked the effects of autologous blood injection on hematoma expansion in diabetic animals. PKal has been reported to mediate plasminogen activation $(99,100)$, which could potentially increase fibrinolysis in the ICH model. However, intracerebral injection of neither tPA nor plasmin mimicked the effects of PKal on hematoma expansion in diabetic animals (17). Moreover, covalently deactivated PKal also induced hemorrhage in this model, suggesting that PKal's effects in this model were not mediated by its catalytic activity. The effects of hyperglycemia and PKal on ICH are rapid, within $30 \mathrm{~min}$, suggesting an effect on an early step in hemostasis. Since in vitro studies have shown that $\mathrm{PKal}$ binding to collagen interferes with its effects on GPVI-mediated platelet activation, these findings suggest that PKal may decrease platelet plug formation, which plays an early step in hemostasis.

\section{Thrombolysis}

Tissue plasminogen activator is the only approved treatment for thrombotic stroke (101). While its prompt administration of tPA following stroke onset has been shown to improve clinical outcomes, its use is limited due to an increased risk of intracranial hemorrhage when tPA is used after the recommended $3 \mathrm{~h}$ therapeutic window, which can negate the potential benefits of vascular recanalization. Although the mechanisms that mediate the increase in hemorrhage induced by tPA are not fully understood, we have shown that both PPK and FXII deficiency markedly reduce tPA-induced hemorrhagic conversion in mice with a thrombotic middle cerebral artery occlusion (20). Studies using purified proteins, as well as plasma, revealed that plasmin activates FXII and cleaves it into a fragment with a molecular weight slightly higher than the expected size of FXIIa light chain generated with PKal (20, 102-105). Plasmin cleaves 
FXII at Arg353 leads to zymogen activation and the generation of FXIIa (104). Plasmin's effects on FXIIa activity is markedly increased in the presence of dextran sulfate (104) and inhibited by e-aminocaproic acid and a FXIIa inhibitory mAb (105). These reports have suggested that plasmin-mediated cleavage of FXII increases FXIIa-like activity. The consequences of plasminmediated cleavage of FXII at Lys346 on FXIIa-like catalytic activity are not yet available. Plasmin-mediated cleavage of FXII could facilitate its autoactivation and/or cleavage by PKal in plasma, which would thereby activate the kallikrein-kinin system.

These findings have suggested that the CAS may either worsen vascular damage or impair hemostasis in the cerebral vasculature following tPA administration. Studies using human plasma have shown that tPA's effects on the CAS are mediated by plasmin (20), which has been identified as a physiological activator of the CAS $(104,105)$. Although the clinical significance of this pathway in hemorrhagic conversion in ischemic stroke is not yet available, two lines of evidence support the conclusion that tPA therapy activates the CAS in stroke patients. First, a recent report by Marcos-Contreras and colleagues has shown that intravenous infusion of tPA in patients result in plasma $\mathrm{HK}$ cleavage (106), suggesting that the tPA activates the circulating CAS. Second, tPA therapy can cause orolingual angioedema that has been attributed to increased BK action $(107,108,109)$, suggesting that TPA increases CAS activity. In addition to reducing hemorrhage, PPK, and FXII deficiency also reduced infarct volume and cerebral edema in mice with stroke treated with tPA. These findings are consistent with previous reports showing that blockade of the CAS has neuroprotective effects in mice with filament-mediated middle cerebral artery occlusion $(85,110)$. Although it is tempting to speculate that inhibition of either PKal or FXIIa during the administration of tPA may ameliorate hemorrhagic transformation and provide neuroprotection during thrombolytic therapy, additional information on the role of the CAS on stroke outcomes in animal models is needed.

\section{THERAPEUTIC IMPLICATIONS AND CONCLUSION}

Currently available anticoagulants used for prevention or treatment of thromboembolic events [heparins, vitamin $\mathrm{K}$ antagonists (for example, warfarin), and inhibitors of thrombin

\section{REFERENCES}

1. Renne T, Schmaier AH, Nickel KF, Blomback M, Maas C. In vivo roles of factor XII. Blood (2012) 120:4296-303. doi:10.1182/blood-2012-07-292094

2. Schmaier AH. Physiologic activities of the contact activation system. Thromb Res (2014) 133:S41-4. doi:10.1016/j.thromres.2014.03.018

3. Ivanov I, Matafonov A, Sun MF, Cheng Q, Dickeson SK, Verhamme IM, et al. Proteolytic properties of single-chain factor XII: a mechanism for triggering contact system. Blood (2017) 129:1527-37. doi:10.1182/ blood-2016-10-744110

4. Samuel M, Pixley RA, Villanueva MA, Colman RW, Villanueva GB. Human factor XII (Hageman factor) autoactivation by dextran sulfate. Circulation dichroism, fluorescence, and ultraviolet difference spectroscopic studies. J Biol Chem (1992) 267:19691-7. or factor Xa] all target enzymes of the coagulation cascade that are essential for the formation of fibrin, a protein necessary for controlling injury-related blood loss. As a result, currently used anticoagulants increase the risk of bleeding and are associated with an increase risk in potentially life-threatening hemorrhage (111). Bleeding is the primary complication of anticoagulation therapy and a significant risk of all currently used anticoagulants, even when maintained within their therapeutic ranges (112). The CAS exerts effects on coagulation at multiple levels. CAS activation of PPK has been implicated in promoting spontaneous microvascular bleeding and the impairment of collageninduced platelet activation. In addition, both PPK and FXII, via activation of the intrinsic coagulation cascade promotes clot stabilization and growth. Feedback activation of FXI by thrombin contributes to clot stabilization and may explain the lack of dependence of hemostasis on FXII and PPK. PKal has been implicated in promoting spontaneous microvascular bleeding and the impairment of collagen-induced platelet activation. Pharmacological blockade of PKal has been shown to provide beneficial effects on cerebral hemostasis in animal models. Although inhibition of the CAS reduces provoked arterial and venous thrombosis in animal models, the clinical significance of the CAS in thrombosis is not yet available. The clinical indications for targeting the CAS for thrombosis will require the identification of thrombotic processes that are dependent on the CAS, which potentially include interactions with artificial surfaces and disease processes that generate factors that activate FXII. In addition, inhibition of the CAS may provide an opportunity to reduce cerebral hemorrhage, which is one of the primary concerns of increased bleeding risk associated with current antithrombotics.

\section{AUTHOR CONTRIBUTIONS}

FS and EF performed literature searches and wrote the manuscript.

\section{FUNDING}

This work was supported by grants from the National Institute of Neurological Disorders and Stroke, National Institutes of Health (NS077006) (EF) and National Institute of Diabetes and Digestive and Kidney Diseases, National Institutes of Health (DK036836) (Joslin's DRC grant).
5. Kaplan AP, Joseph K. Pathogenic mechanisms of bradykinin mediated diseases: dysregulation of an innate inflammatory pathway. Adv Immunol (2014) 121:41-89. doi:10.1016/B978-0-12-800100-4.00002-7

6. Leed-Lundberg LM, Marceau F, Muller-Esterl W, Pettibone DJ, Zuraw BL. International union of pharmacology. XLV. Classification of the kinin receptor family: from molecular mechanisms to pathophisiological consequences. Pharmacol Rev (2005) 57:27-77. doi:10.1124/pr.57.1.2

7. Han ED, MacFarlane RC, Mulligan AN, Scafidi J, Davis AE III. Increased vascular permeability in Clinhibitor-deficent mice mediated by the bradykinin type 2 receptor. J Clin Invest (2002) 109:1057-63. doi:10.1172/ JCI200214211

8. Cicardi M, Banerji A, Bracho F, Malbrán A, Rosenkranz B, Riedl M, et al. Icatibant, a new bradykinin-receptor antagonist, in hereditary angioedema. N Engl J Med (2010) 363:532-41. doi:10.1056/NEJMoa0906393 
9. Banerji A, Busse O, Shennak M, Lumry W, Davis-Lorton M, Wedner HJ, et al. Inhibiting Plasma Kallikrein for Hereditary Angioedema Prophylaxis. Engl J Med (2017) 376:717-28. doi:10.1056/NEJMoa1605767

10. Brown NJ, Gainer JV, Murphey LJ, Vaughan DE. Bradykinin stimulates tissue plasminogen activator release from human forearm vasculature through $\mathrm{B}(2)$ receptor-dependent, NO synthase-independent, and cyclooxygenase-independent pathway. Circulation (2000) 102:2190-6. doi:10.1161/01. CIR.102.18.2190

11. Minai K, Matsumoto T, Horie H, Ohira N, Takashima H, Yokohama H, et al. Bradykinin stimulates the release of tissue plasminogen activator in human coronary circulation: effects of angiotensin-converting enzyme inhibitors. J Am Coll Cardiol (2001) 37:1565-70. doi:10.1016/ S0735-1097(01)01202-5

12. Kimura S, Tsuji H, Nishimura H, Kato H, Ukimura N, Yano S, et al. Bradykinin enhances in vitro procoagulant and antifibrinolytic properties of rat vascular endothelial cells. Thromb Res (2002) 106:41-50. doi:10.1016/ S0049-3848(02)00070-1

13. Stavrous EX, Fang C, Merkulova A, Alhalabi O, Grobe N, Antoniak S, et al. Reduced thrombosis in klkb1-/- mice is mediated by increased Mas receptor, prostacyclin, Sirt1, and KLF4 and decreased tissue factor. Blood (2015) 125:710-9. doi:10.1182/blood-2014-01-550285

14. Davie EW, Ratnoff OD. Waterfall sequence for intrinsic blood clotting. Science (1964) 145:1310-2. doi:10.1126/science.145.3638.1310

15. Gailani D, Neff AT. Rare coagulation factor deficiencies. 5th ed. In: Hoffman H, Benze EJ, Shattil SJ, Furie B, Silberstein LE, McGlave P, Heslop H, editors. Hematology, Basic Principles and Practice. Philadelphia, PA: Churcill Livingstone-Elsevier (2009). p. 1939-52.

16. Renne T, Pozgajova M, Gruner S, Schuh K, Pauer HU, Burfeind P, et al. Defective thrombus formation in mice lacking coagulation factor XII. J Exp Med (2005) 202:271-81. doi:10.1084/jem.20050664

17. Liu J, Gao BB, Clermont AC, Blair P, Chilcote TJ, Sinha S, et al. Hyperglycemiainduced cerebral hematoma expansion is mediated by plasma kallikrein. Nat Med (2011) 17:206-10. doi:10.1038/nm.2295

18. Bird JE, Smith PL, Wang X, Schumacher WA, Barbera F, Revelli JP, et al. Effects of plasma kallikrein deficiency on haemostasis and thrombosis in mice: murine ortholog of the Fletcher trait. Thromb Haemost (2012) 107:1141-50. doi:10.1160/TH-11-10-0682

19. Kokoye Y, Ivanov I, Cheng Q, Matafonov A, Dickeson SK, Mason S, et al. A comparison of the effects of factor XII deficiency and prekallikrein deficiency on thrombus formation. Thromb Res (2016) 140:118-24. doi:10.1016/j. thromres.2016.02.020

20. Simao F, Ustunkaya T, Clermont AC, Feener EP. Plasma kallikrein mediates brain hemorrhage and edema caused by tissue plasminogen activator therapy in mice after stroke. Blood (2017) 129:2280-90. doi:10.1182/ blood-2016-09-740670

21. Xue J, Wu Q, Westfield LA, Tuley EA, Lu D, Zhang Q, et al. Incomplete embryonic lethality and fatal neonatal hemorrhage caused by prothrombin deficiency in mice. Proc Natl Acad Sci U S A (1998) 95:7603-7. doi:10.1073/ pnas. 95.13 .7603

22. Iwaki T, Cruz-Topete D, Castellino FJ. A complete factor XII deficiency does not affect coagulopathy, inflammatory response, and lethality, but attenuates early hypotension in endotoxemic mice. J Thromb Haemost (2008) 6:1993-5. doi:10.1111/j.1538-7836.2008.03142.x

23. Matafonov A, Leung PY, Gailani AE, Grach SL, Puy C, Cheng Q, et al. Factor XII inhibition reduces thrombus formation in a primate thrombosis model. Blood (2014) 123:1739-46. doi:10.1182/blood-2013-04-499111

24. Revenko AS, Gao D, Crosby JR, Bhattacharjee G, Zhao C, May C, et al. Selective depletion of plasma kallikrein or coagulation factor XII inhibits thrombosis in mice without increased risk of bleeding. Blood (2011) 118:5302-11. doi:10.1182/blood-2011-05-355248

25. Nickel KF, Ronquist G, Langer F, Labberton L, Fuchs TA, Bokemeyer C, et al. The polyphosphate-factor XII pathway drives coagulation in prostate cancer-associated thrombosis. Blood (2015) 126:1379-89. doi:10.1182/ blood-2015-01-622811

26. Hagedorn I, Schmidbauer S, Pleines I, Kleinschnitz C, Kronthaler U, Stoll G, et al. Factor XIIa inhibitor recombinant human albumin infestin-4 abolishes occlusive arterial thrombus formation without affecting bleeding. Circulation (2010) 121:1510-7. doi:10.1161/CIRCULATIONAHA.109. 924761
27. Cai TQ, Wu W, Shin MK, Xu Y, Jochnowitz N, Zhou Y, et al. Factor XII full and partial null in rat confers robust antithrombotic efficacy with no bleeding. Blood Coagul Fibrinolysis (2015) 26:893-902. doi:10.1097/ MBC. 0000000000000337

28. Merkulov S, Zhang WM, Komar AA, Schmaier AH, Barnes E, Zhou Y, et al. Deletion of murine kininogen gene 1 (mKng1) causes loss of plasma kininogen and delays thrombosis. Blood (2008) 111:1274-81. doi:10.1182/ blood-2007-06-092338

29. Shariat-Madar Z, Mahdi F, Warnock M, Homeister JW, Srikanth S, Krijanovski Y, et al. Bradykinin B2 receptor knockout mice are protected from thrombosis by increased nitric oxide and protacyclin. Blood (2006) 108:192-9. doi:10.1182/blood-2006-01-0094

30. Liu J, Clermont AC, Gao BB, Feener EP. Intraocular hemorrhage causes retinal vascular dysfunction via plasma kallikrein. Invest Ophthalmol Vis Sci (2013) 54:1086-94. doi:10.1167/iovs.12-10537

31. Arai M, Yamamoto N, Moroi M, Akamatsu N, Fukutake K, Tanoue K. Platelets with $10 \%$ of the normal amount of glycoprotein VI have an impaired response to collagen that results in a mild bleeding tendency. $\mathrm{Br} J$ Hematol (2001) 67:262-7. doi:10.1111/j.1365-2141.1995.tb08900.x

32. Stulz CM, Edelman ER. A structural model that explains the effects of hyperglycemia on collagenolysis. Biophys J (2003) 85:2198-204. doi:10.1016/ S0006-3495(03)74645-1

33. Yoshida S, Sudo T, Niimi M, Tao L, Sun B, Kambayashi J, et al. Inhibition of collagen-induced platelet aggregation by anopheline antiplatelet protein, a saliva protein from a malaria vector mosquito. Blood (2008) 111:2007-14. doi:10.1182/blood-2007-06-097824

34. White-Adams TC, Berny MA, Patel IA, Tucker EI, Gailani D, Gruber A, et al. Laminin promotes coagulation and thrombus formation in a factor XII-dependent manner. J Thromb Haemost (2010) 8:1295-301. doi:10.1111/j. 1538-7836.2010.03850.x

35. Wilner GD, Nossel HL, LeRoy EC. Activation of Hageman factor by collagen. J Clin Invest (1968) 47:2608-15. doi:10.1172/JCI105943

36. Pedicord DL, Seiffert D, Blat Y. Feedback activation of factor XI by thrombin does not occur in plasma. Proc Natl Acad Sci U S A (2007) 104:12855-60. doi:10.1073/pnas.0705566104

37. Naito K, Fujikawa K. Activation of human blood coagulation factor XI independent of factor XII. Factor XI is activated by thrombin and factor Xia in the presence of negatively charged surfaces. J Biol Chem (1991) 266:7353-8.

38. Gailani D, Broze GJ Jr. Factor XI activation in a revised model of blood coagulation. Science (1991) 253:909-12. doi:10.1126/science.1652157

39. Bouma BN, von dem Borne PA, Meijers JC. Factor XI and protection of the fibrin clot against lysis - a role for the intrinsic pathway of coagulation in fibrinolysis. Thromb Haemost (1998) 80:24-7.

40. Verhoef JJ, Barendrecht AD, Nickel KF, Dijkxhoorn K, Kenne E, Labberton L, et al. Polyphosphate nanoparticles on the platelet surface trigger contact system activation. Blood (2017) 129:1707-17. doi:10.1182/blood-2016-08-734988

41. Cheng Q, Tucker EI, Pine MS, Sisler I, Matafonov A, Sun MF, et al. A role for factor XIIa-mediated factor XI activation in thrombus formation in vivo. Blood (2010) 116:3981-9. doi:10.1182/blood-2010-02-270918

42. Nossel HL, Wilner GD, LeRoy EC. Importance of polar groups for initiating blood coagulation and aggregation platelets. Nature (1969) 221:75-6. doi:10.1038/221075a0

43. van der Meijden PE, Munnix IC, Auger JM, Govers-Riemslag JW, Cosemans JM, Kuijpers MJ, et al. Dual role of collagen in factor XIIdependent thrombus formation. Blood (2009) 114:881-90. doi:10.1182/ blood-2008-07-171066

44. Von dem Borne PA, Bajzar L, Meijers JC, Nesheim ME, Bouma BN. Thrombin-mediated activation of factor XI results in a thrombin-activatable fibrinolysis inhibitor-dependent inhibition of fibrinolysis. J Clin Invest (1997) 99:2323-7. doi:10.1172/JCI119412

45. Puy C, Tucker EI, Matafonov A, Cheng Q, Zientek KD, Gailani D, et al. Activated factor XI increases the procoagulant activity of the extrinsic pathway by inactivating tissue factor pathway inhibitor. Blood (2015) 125:1488-96. doi:10.1182/blood-2014-10-604587

46. Plötz FB, van Oeveren W, Bartlett RH, Wildevuur CR. Blood activation during neonatal extracorporeal life support. J Thorac Cardiovasc Surg (1993) 105:823-32.

47. Wendel HP, Jones DW, Gallimore MJ. FXII levels, FXIIa-like activities and kallikrein activities in normal subjects and patients undergoing 
cardiac surgery. Immunopharmacology (1999) 45:141-4. doi:10.1016/ S0162-3109(99)00067-3

48. Larsson M, Rayzman V, Nolte MW, Nickel KF, Björkqvist J, Jämsä A, et al. A factor XIIa inhibitory antibody provides thromboprotection in extracorporeal circulation without increasing bleeding risk. Sci Transl Med (2014) 6:222ra17. doi:10.1126/scitranslmed.3006804

49. Cei M, Mumoli N, Giumtoli S, Marino P, Pasquinelli P, Taddei P, et al. Concomitant ST-elevation myocardial infarction and deep vein thrombosis in a patient with severe factor XII deficiency: case report and review of the literature. QJM (2011) 104:1083-6. doi:10.1093/qjmed/hcq221

50. Lessiani G, Falco A, Nicolucci E, Rolandi G, Daví G. Deep venous thrombosis and previous myocardial infarction in mild factor XII deficiency: a risk factor for both venous and arterial thrombosis. J Thromb Thrombolysis (2009) 27:348-51. doi:10.1007/s11239-008-0222-1

51. Conaglen PJ, Akowuah E, Theodore S, Atkinson V. Implications for cardiac in patients with factor XII deficiency. Ann Thorac Surg (2010) 89:625-6. doi:10.1016/j.athoracsur.2009.07.042

52. Hellstern P, Köhler M, Schmengler K, Doenecke P, Wenzel E. Arterial and venous thrombosis and normal response to streptokinase treatment in young patient with severe Hageman factor deficiency. Acta Haematol (1983) 69:123-6. doi:10.1159/000206872

53. Moorman RM, Reynolds DS, Comunale ME. Management of cardiopulmonary bypass in a patient with congenital factor XII deficiency. J Cardiothorac Vasc Anesth (1993) 7:452-4. doi:10.1016/1053-0770(93)90169-L

54. Penny WJ, Colvin BT, Brooks N. Myocardial infarction with normal coronary arteries and factor XII deficiency. Br Heart J (1985) 53:230-4. doi:10.1136/ hrt.53.2.230

55. Rygal P, Kuc A. Perioperative management of cardiac surgery patients with factor XII deficiency-two case reports. Anaethesiol Intensive Ther (2012) 44:244-47.

56. Cronbaugh RD, Fuller LA, Miller SD, Richenbacher WE. Cardiopulmary bypass in a patient with factor XII deficiency. J Extra Corpor Technol (2014) 46:251-3.

57. Salmenper M, Rasi V, Mattila S. Cardiopulmonary bypass in a patient with factor XII deficiency. Anesthesiology (1991) 75:539-41. doi:10.1097/00000542-199109000-00027

58. van Veen JJ, Laidlaw S, Swanevelder J, Harvey N, Watson C, Kitchen S, et al. Contact factor deficiencies and cardiopulmonary bypass surgery: detection of the defect and monitoring of heparin. Eur J Haematol (2009) 82:208-12. doi:10.1111/j.1600-0609.2008.01191.x

59. Wood MK. Congenital factor XII deficiency and cardiopulmonary bypass. Ann Thorac Surg (1994) 52:1565. doi:10.1016/0003-4975(94)91976-3

60. Vergnes C, Lorient-Roudaut MF, Haissaguerre M, Roudaut R, Wicker P, Boisseu MR, et al. Thrombophlebitis and pulmonary embolism in congenital factor XII deficiency. Arch Mal Coeur Vaiss (1985) 78:440-3.

61. Borrego-Sanz L, Santos-Bueso E, Sáenz-Francés F, Martínez-de-la-Casa JM, García-Feijoo J, Gegúndez-Fernández JA, et al. Retinal venous thrombosis in a young patient with coagulation factor XII deficiency. Arch Soc Esp Oftalmol (2014) 89:329-31. doi:10.1016/j.oftal.2013.06.006

62. Cornudella R, Puente F, Hortells JL, Gutiérrez M. Moderate deficiency of Factor XII associated with postoperative deep venous thrombosis. Sangre (Barc) (1989) 34:144-6.

63. Gerhardt MA, Greenberg CS, Slaughter TF, Stafford Smith M. Factor XII deficiency and cardiopulmonary bypass: use of a novel modification of the activated clotting time to monitor anticoagulation. Anesthesiology (1997) 87:990-2. doi:10.1097/00000542-199710000-00038

64. Oram MP, Mumford AD, Morse C, Underwood S. Management of anticoagulation for coronary artery bypass surgery in a patient with severe prekallikrein deficiency. J Cardiothorac Vasc Anesth (2006) 20:580-2. doi:10.1053/j.jvca.2005.09.001

65. Cankovic L, Steenwyk BL, McGiffin DC, Nielsen VG. Practical approach to anticoagulation for cardiopulmonary bypass in the patient with congenital prolonged activated partial thromboplastin time. Blood Coagul Fibrinolysis (2008) 19:725-6. doi:10.1097/MBC.0b013e32830891ab

66. Asmis LM. The characteristic normalization of the severely prolonged aPTT following increased preincubation time is due to autoactivation of factor XII. Thromb Res (2002) 105:463-70. doi:10.1016/S0049-3848(02) 00045-2
67. Maak B, Kochhan L, Heuchel P, Jenderny J. Severe prekallikrein deficiency due to a compound heterozygosis in the KLKB1-gene. Hamostaseologie (2009) 29:187-9.

68. DeLa Cadena RA. Fletcher factor deficiency in a 9-year-old girl: mechanisms of the contact pathway of blood coagulation. Am J Hematol (1995) 48:273-7. doi:10.1002/ajh.2830480413

69. Francois D, Trigui N, Leterreux G, Flaujac C, Horellou MH, Mazaux L, et al. Severe prekallikrein deficiencies due to homozygous C529Y mutations. Blood Coagul Fibrinolysis (2007) 18:283-6. doi:10.1097/MBC. 0b013e328010bcde

70. Nakao T, Yamane T, Katagami T, Shiota M, Izumi Y, Samori T, et al. Severe prekallikrein deficiency due to a homozygous Trp499Stop nonsense mutation. Blood Coagul Fibrinolysis (2011) 22:337-9. doi:10.1097/ MBC.0b013e3283444ddb

71. Lombardi AM, Sartori MT, Cabrio L, Fadin M, Zanon E, Girolami A. Severe prekallikrein (Fletcher factor) deficiency due to a compound heterozygosis (383TRp stop codon and Cys529Tyr). Thromb Haemost (2003) 90:1040-5. doi:10.1160/TH03-05-0275

72. Wynne Jones D, Russel G, Allford SL, Burdon K, Hawkins GA, Bowden DW, et al. Severe prekallikrein deficiency associated with homozygosity for an Arg94Stop nonsense mutation. Br J Haematol (2004) 127:220-3. doi:10.1111/j.1365-2141.2004.05180.x

73. Poon MC, Moore MR, Castleberry RP, Lurie A, Huang ST, Lehmeyer J. Severe Fletcher factor (plasma kallikrein) deficiency with partial deficiency of Hageman factor (factor XII): report of a case with observation on in vivo and in vitro leukocyte chemotaxis. Am J Hematol (1982) 12:261-70. doi:10.1002/ ajh. 2830120308

74. Davidson SJ, Burman JF, Rutherford LC, Keogh BF, Yacoub MH. High molecular kininogen deficiency: a patient who underwent cardiac surgery. Thromb Haemost (2001) 85:195-7.

75. Lefrere JJ, Horellou MH, Gozin D, Conard J, Muller JY, Clark M, et al. A new case of high-molecular-weight kininogen inherited deficiency. Am J Hematol (1986) 22:415-9. doi:10.1002/ajh.2830220411

76. Stormorken H, Briseid K, Hellum B, Hoem NO, Johansen HT, Ly B. A new case of total kininogen deficiency. Thromb Res (1990) 60:457-67. doi:10.1016/0049-3848(90)90230-A

77. Krijanovski Y, Proulle V, Mahdi F, Dreyfus M, Muller-Esterl W, Schmaier AH. Characterization of molecular defects of Fitzgerald trait and another novel high-molecular-weight kininogen-deficient patient: insight into structural requirements for kininogen expression. Blood (2003) 101:4430-6. doi:10.1182/blood-2002-11-3329

78. Zeerleder S, Schloesser M, Redondo M, Wuillemin WA, Engel W, Furlan M, et al. Reevaluation of the incidence of thromboembolic complications in congenital factor XII deficiency a study on 73 subjects from 14 Swiss families. Thromb Haemost (1999) 82:1240-6.

79. Girolami A, Candeo N, De Marinis GB, Bonamigo E, Girolami B. Comparative incidence of thrombosis in reported cases of deficiencies of factors of the contact phase of blood coagulation. J Thromb Thrombolysis (2011) 31:57-63. doi:10.1007/s11239-010-0495-Z

80. Longhurst H, Circardi M. Hereditary angio-edema. Lancet (2012) 379: 474-81. doi:10.1016/S0140-6736(11)60935-5

81. Cugno M, Cicardi M, Bottasso B, Coppola R, Paonessa R, Mannucci PM, et al. Activation of the coagulation cascade in $\mathrm{C} 1$-inhibitor deficiencies. Blood (1997) 89:3213-8.

82. Bork K, Witzke G. Shortened activated partial thromboplastin time may help in diagnosing hereditary and acquired angioedema. Int Arch Allergy Immunol (2016) 170:101-7. doi:10.1159/000447695

83. Csuka D, Veszeli N, Imreh E, Zotter Z, Skopal J, Prohaszka Z, et al. Comprehensive study into the activation of the plasma enzyme systems during attacks of hereditary angioedema due to C1-inhibitor deficiency. Orphanet J Rare Dis (2015) 10:132. doi:10.1186/s13023-0150351-5

84. van Geffen M, Cugno M, Lap P, Loof A, Cicardi M, van Heerde W. Alterations of coagulation and fibrinolysis in patients with angioedema due to C1-inhibitor. Clin Exp Immunol (2012) 167:472-8. doi:10.1111/j. 1365-2249.2011.04541.x

85. Kleinschnitz C, Stoll G, Bendszus M, Schuh K, Pauer HU, Burfeind P, et al. Targeting coagulation factor XII provides protection from pathological 
thrombosis in cerebral ischemia without interfering with hemostasis. J Exp Med (2006) 203:513-8. doi:10.1084/jem.20052458

86. Muller F, Chenk WA, Smith SA, Esterl L, Spronk HM, Schmidbauer S, et al. Platelet polyphosphate are proinflammatory and progoagulant mediators in vivo. Cell (2009) 139:1143-56. doi:10.1016/j.cell.2009.11.001

87. Rosen ED, Gailani D, Castellino FJ. FXI is essential for thrombus formation following FeCl3-induced injury of the carotid artery in the mouse. Thromb Haemost (2002) 87:774-6.

88. Wang X, Cheng Q, Xu L, Feuerstein GZ, Hsu MY, Smith PL, et al. Effects of factor IX or XI deficiency on ferric chloride-induced carotid artery occlusion in mice. J Thromb Haemost (2005) 3:695-702. doi:10.1111/j.1538-7836.2005. 01236.x

89. Harpel PC. Studies on the interaction between collagen and a plasma kallikrein-like activity. Evidence for a surface-active enzyme system. J Clin Invest (1972) 51:1813-22. doi:10.1172/JCI106983

90. Yau JW, Rogers SL, Kawasaki R, Lamoureux EL, Kowalski JW, Bek T, et al. Global prevalence and major risk factors of diabetic retinopathy. Diabetes Care (2012) 35:556-64. doi:10.2337/dc11-1909

91. Gao BB, Chen X, Timothy N, Aiello LP, Feener EP. Characterization of the vitreous proteome in diabetes without diabetic retinopathy and diabetes with proliferative diabetic retinopathy. J Proteome Res (2008) 7:2516-25. doi:10.1021/pr800112g

92. Kita T, Clermont AC, Murugesan N, Zhou Q, Fujisawa K, Ishibashi T, et al. Plasma kallikrein-kinin system as a VEGF-independent mediator of diabetic macular edema. Diabetes (2015) 64:3588-99. doi:10.2337/db15-0317

93. Loukovaara S, Nurkkala H, Tamene F, Gucciardo E, Liu X, Repo P, et al. Quantitative proteomics analysis of vitreous humor from diabetic retinopathy patients.J ProteomeRes (2015) 14:5131-43. doi:10.1021/acs.jproteome.5b00900

94. Clermont A, Chilcote TJ, Kita T, Liu J, Riva P, Sinha S, et al. Plasma kallikrein mediates retinal vascular dysfunction and induces retinal thickening in diabetic rats. Diabetes (2011) 60:1590-8. doi:10.2337/db10-1260

95. Liu J, Gao BB, Feener EP. Proteomic identification of novel plasma kallikrein substrate in the astrocyte secretome. Trans Stroke Res (2010) 1:276-86. doi:10.1007/s12975-010-0039-z

96. Appelboom G, Piazza MA, Hwang BY, Carpenter A, Bruce SS, Mayer S, et al. Severity of intraventricular extension correlates with level of admission glucose after intracerebral hemorrhage. Stroke (2011) 42:1883-8. doi:10.1161/ STROKEAHA.110.608166

97. Arboix A, Massons J, García-Eroles L, Oliveres M, Targa C. Diabetes is an independent risk factor for in-hospital mortality from acute spontaneous intracerebral hemorrhage. Diabetes Care (2000) 23:1527-32. doi:10.2337/ diacare.23.10.1527

98. Lee SH, Kim BJ, Bae HJ, Lee JS, Lee J, Park BJ, et al. Effects of glucose level on early and long-term mortality after intracerebral haemorrhage: the Acute Brain Bleeding Analysis Study. Diabetologia (2010) 53:429-34. doi:10.1007/ s00125-009-1617-z

99. Selvarajan S, Lund LR, Takeuchi T, Craik CS, Werb Z. A plasma kallikreindependent plasminogen cascade required for adipocyte differentiation. Nat Cell Biol (2001) 3:267-75. doi:10.1038/35060059

100. Coleman RW. Activation of plasminogen by human plasma kallikrein. Biochem Biophys Res Commun (1969) 35:273-9. doi:10.1016/0006-291X(69)90278-2
101. Hacke W, Kaste M, Bluhmki E, Brozman M, Davalos A, Guidetti D, et al. Thrombolysis with alteplase 3 to 4.5 hours after acute ischemic stroke. $N$ Engl J Med (2008) 359:1317-29. doi:10.1056/NEJMoa0804656

102. Kaplan AP, Austen KF. A prealbumin activator of prekallikrein. II. Derivation of activators of prekallikrein form active Hageman factor by digestion with plasmin. J Exp Med (1971) 133:696-712. doi:10.1084/jem.133.4.696

103. Griffin JH. Role of surface in surface-dependent activation of Hageman factor (blood coagulation factor XII). Proc Natl Acad Sci U S A (1971) 75:1998-2002. doi:10.1073/pnas.75.4.1998

104. Ewald GA, Eisenberg PR. Plasmin-mediated activation of contact system in response to pharmacological thrombolysis. Circulation (1995) 91:28-36. doi:10.1161/01.CIR.91.1.28

105. De Maat S, Bjorkqvist J, Suffritti C, Wiesenekker CP, Nagtegaal W, Koekman A, et al. Plasmin is a natural trigger for bradykinin production in patients with hereditary angioedema with factor XII mutations. J Allergy Clin Immunol (2016) 138:1414-23.e9. doi:10.1016/j.jaci.2016.02.021

106. Marcos-Contreras OA, Martinez de Lizarrondo S, Bardou I, Orset C, Pruvost M, Anfray A, et al. Hyperfibrinolysis increases blood brain barrier permeability by a plasmin and bradykinin-dependent mechanism. Blood (2016) 128:2423-34. doi:10.1182/blood-2016-03-705384

107. Myslimi F, Caparros F, Dequatre-Ponchelle N, Moulin S, Gautier S, Girardie $\mathrm{P}$, et al. Orolingual angioedema during or after thrombolysis for cerebral ischemia. Stroke (2016) 47:1825-30. doi:10.1161/STROKEAHA.116. 013334

108. Lekoubou A, Phillippeau F, Derex L, Olaru A, Gouttard M, Vieillart A, et al. Audit report and systematic review of orolingual angioedema in post-acute stroke thrombolysis. Neurol Res (2014) 36:687-94. doi:10.1179/17431328 13Y.0000000302

109. Molinaro G, Gervais N, Adam A. Biochemical basis of angioedema associated with recombinant tissue plasminogen activator treatment: an in vitro experimental approach. Stroke (2002) 33:1712-6. doi:10.1161/01. STR.0000017284.77838.87

110. Gob E, Reymann S, Langhauser F, Schuhmann MK, Kraft P, Thielmann I, et al. Blocking of plasma kallikrein ameliorates stroke by reducing thromboinflammation. Ann Neurol (2015) 77:784-803. doi:10.1002/ana.24380

111. Mega JL, Simon T. Pharmacology of antithrombotic drugs: an assessment of oral antiplatelet and anticoagulant treatments. Lancet (2015) 386:281-91. doi:10.1016/S0140-6736(15)60243-4

112. Ng HJ, Crowther MA. New anti-thrombotic agents: emphasis on hemorrhagic complications and their management. Semin Hematol (2006) 43:S77-83. doi:10.1053/j.seminhematol.2005.11.023

Conflict of Interest Statement: EPF is an employee of KalVista Pharmaceuticals Inc. (Cambridge, MA, USA). FS declares no competing financial interests.

Copyright $\odot 2017$ Simão and Feener. This is an open-access article distributed under the terms of the Creative Commons Attribution License (CC BY). The use, distribution or reproduction in other forums is permitted, provided the original author(s) or licensor are credited and that the original publication in this journal is cited, in accordance with accepted academic practice. No use, distribution or reproduction is permitted which does not comply with these terms. 